\title{
Primary Diffuse Large B-Cell Lymphoma of Central Nervous System: Is Still Surgery an Unorthodox Treatment?
}

\author{
Ioannis Siasios ${ }^{\mathrm{a}, \mathrm{c}}$, Aggeliki Fotiadou ${ }^{\mathrm{a}}$, George Fotakopoulos ${ }^{\mathrm{a}}$, Maria Ioannou ${ }^{\mathrm{b}}$, \\ Vassilios Anagnostopoulos ${ }^{\text {a }}$, Konstantinos Fountas ${ }^{\text {a }}$
}

\begin{abstract}
Primary central nervous system lymphoma (PCNSL) is characterized as an extra-nodal non-Hodgkin lymphoma which develops from the neuraxis. The purpose was to report a case of a patient with a supra-tentorial tumor who underwent subtotal resection of his tumor as his biopsy was not indicative of a PCNSL tumor and had uneventful recovery until his last follow-up. A 42-year-old man was admitted to our department for generalized epileptic seizures. CT and MRI examinations revealed a tumor in his right parietal-occipital lobe that was surrounded by edema and was enhancing after gadolinium administration. The patient underwent a navigation-assisted parietooccipital craniotomy and posterior parietal transcortical approach for tumor biopsy which was not indicative of PCNSL tumor. The surgical team decided to remove the tumor on site. Histological analysis of the resected specimen showed primary diffuse large B-cell lymphoma. Combined chemotherapy and radiation therapy was applied to the patient, and at his last follow-up (16 months), he is tumor free. In our case as in several other studies during the last decade, the outcome after the surgical resection of a PCNSL tumor in combination to radiation and chemotherapy was unexpectedly good. The role of surgery probably should be reconsidered for single lesion PCNSL tumors.
\end{abstract}

Keywords: Primary CNS lymphoma; Diffuse large B-cell lymphoma; Radiotherapy; Chemotherapy

\section{Introduction}

Primary central nervous system lymphomas (PCNSLs) are nonHodgkin lymphomas that are developing outside the nodules

Manuscript accepted for publication October 14, 2015

a Department of Neurosurgery, University Hospital of Larissa, Mezourlo 1, Larissa 41110, Greece

bepartment of Pathology, University Hospital of Larissa, Mezourlo 1, Larissa 41110, Greece

${ }^{\mathrm{c} C o r r e s p o n d i n g ~ A u t h o r: ~ I o a n n i s ~ S i a s i o s, ~ D e p a r t m e n t ~ o f ~ N e u r o s u r g e r y, ~ U n i v e r-~}$ sity Hospital of Larissa, Mezourlo 1, Larissa 41110, Greece.

Email: siasiosj@med.uth.gr

doi: http://dx.doi.org/10.14740/jocmr2376w and consist only the $3-4 \%$ of primary brain tumors [1-4]. Bailey first described PCNSL as "perithelial sarcoma" of the CNS and Henry in 1974 recognized its lymphoid origin [3]. The majority of these tumors $(95 \%)$ are considered diffuse large B-cell lymphomas (DLBCLs) $[5,6]$. DLBCLs are characterized as high grade and most of them are CD20 positive while the minority of PCNSL consists of types such as Burkitt lymphomas, Burkittlike lymphomas and lymphoblastic lymphomas $[1,7,8]$.

PCNSL typically develops in the fifth to seventh decade of life although its overall incidence has increased in the last decade probably due to technological advances that contribute significantly in the earlier diagnosis [9]. It can be present in the ocular region, spinal cord and CSF $[7,10]$. Supratentorial single lesions occur in about $60-70 \%$ of the patients [11].

Headache, nausea, vomiting, epileptic seizures, disorders of speech and vision and focal neurologic deficits are the most common symptoms of brain lymphomas. Diagnosis requires computer tomography (CT) of the brain, magnetic resonance imaging (MRI), microscopic ocular examination, CSF analysis and biopsy [7]. In case that the biopsy is received from the infiltrative margins of the tumor, PCNSL resembles morphologically to glial tumors, especially oligodendroglioma. Their occurrence is associated with situations involving immune deficiency, such as organ transplantations and HIV [7, 11, 12].

The recommended treatment for these patients includes chemotherapy with or without additional radiotherapy, whereas corticosteroids can be used in addition. Surgery is not recommended for the treatment of brain lymphomas and it is only performed in extreme situations [7]. Generally, PCNSL of DLBCL type is a highly aggressive tumor and although its prognosis is poor, about one-third of younger patients can hope for cure of the disease [13]. In this short communication, authors are presenting a case of a DLBCL tumor which was treated surgically and had an unexpected good outcome.

\section{Case Report}

A 42-year-old right-handed man was referred to our neurosurgery department for generalized epileptic seizures, muscular weakness of both upper and lower limbs, gait instability and headache. The patient was suffering from recurrent seizures since his childhood and was under anticonvulsant treatment with phenobarbital and valproic acid. He was a heavy smoker 


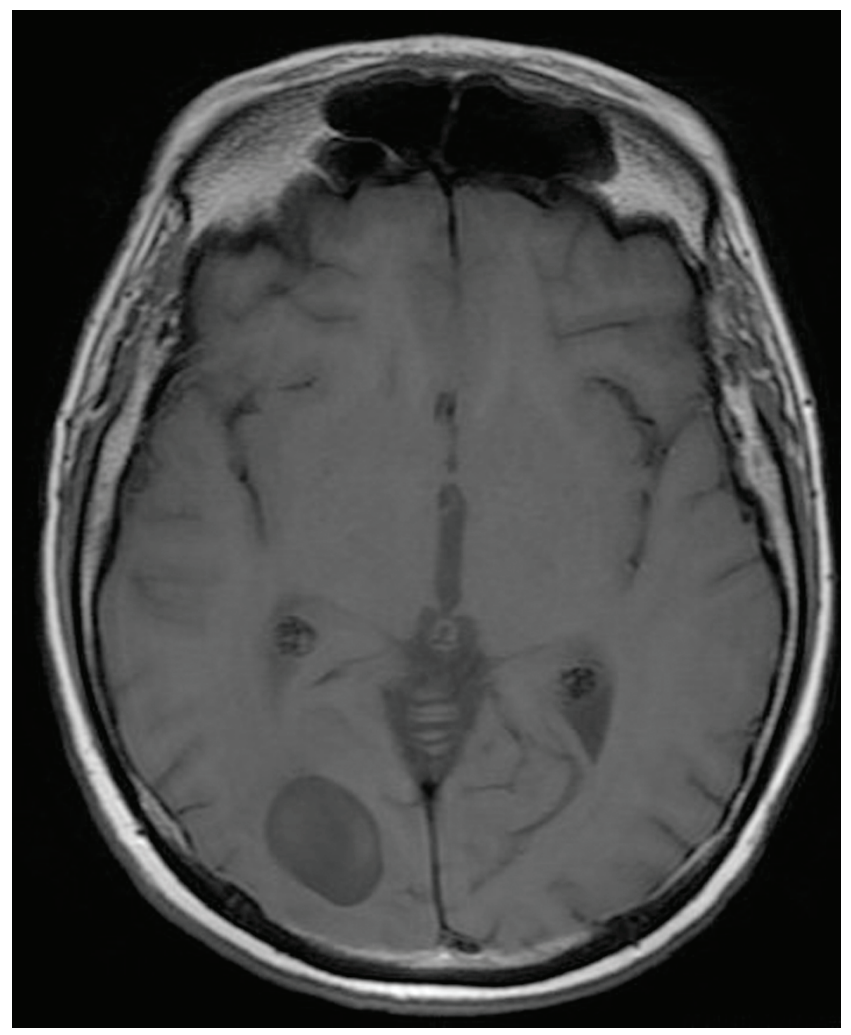

Figure 1. Pre-operative brain MRI T1 sequence.

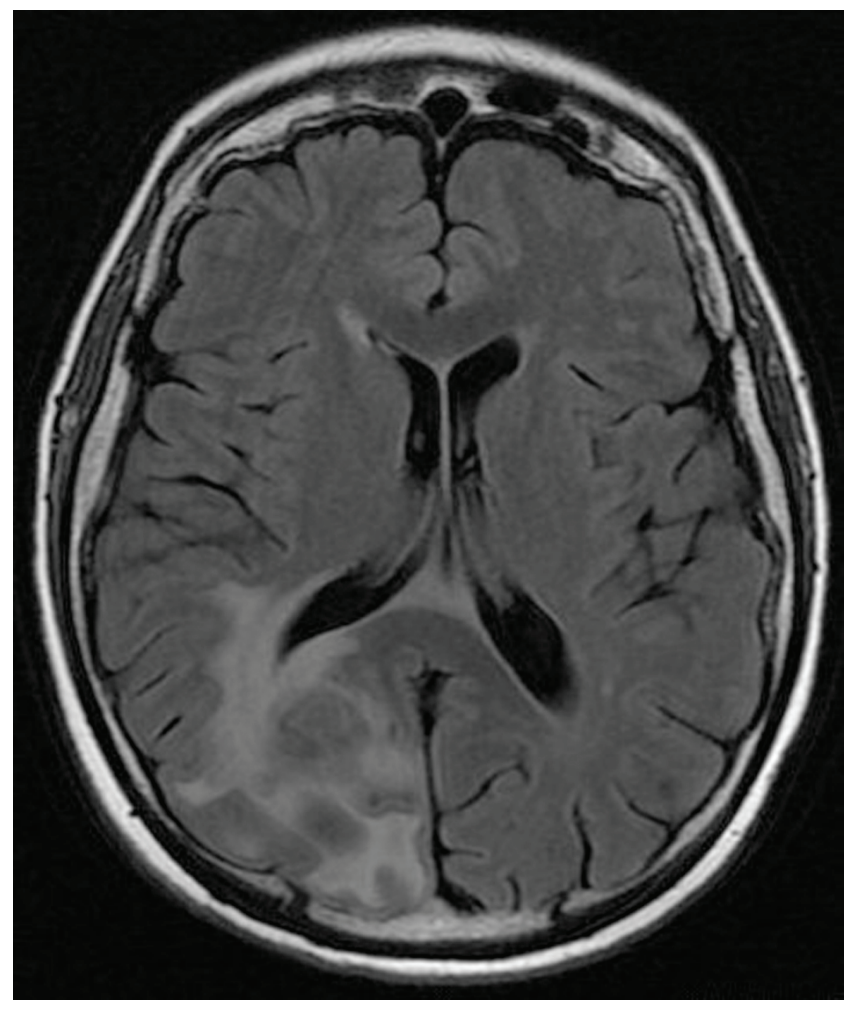

Figure 2. Pre-operative brain MRI FLAIR sequence which shows the peritumoral edema.

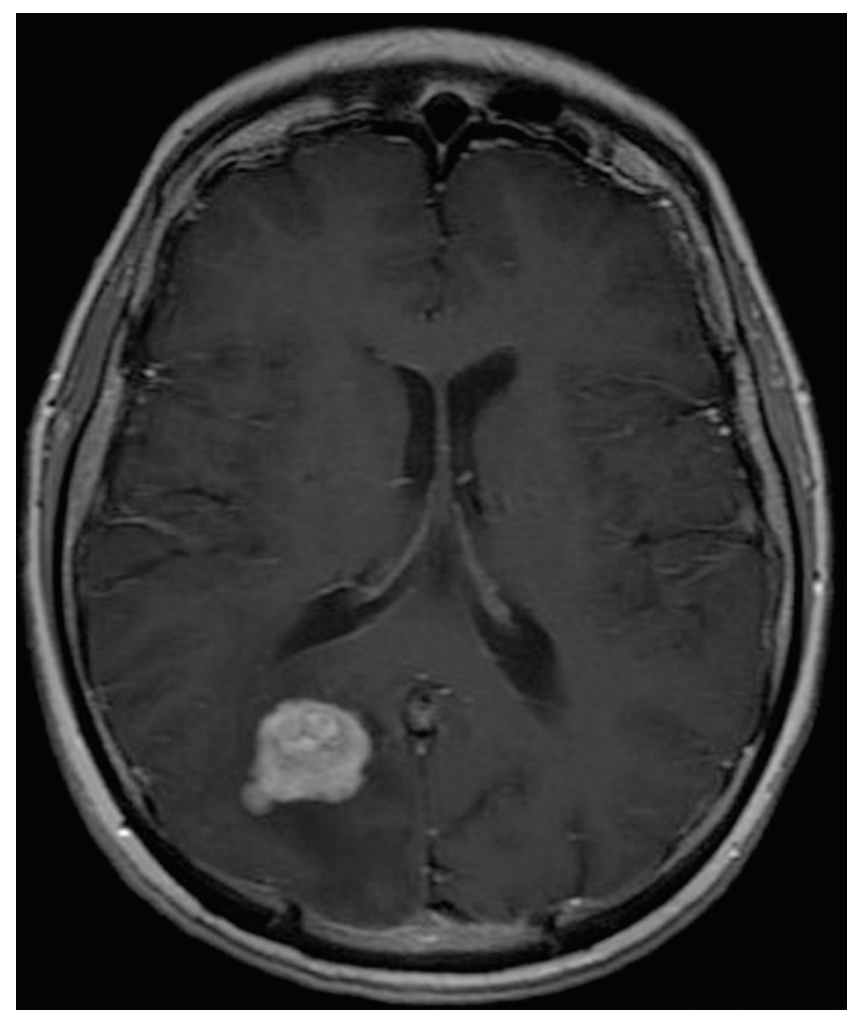

Figure 3. Pre-operative brain MRI T1 sequence with contrast gadolinium which shows the enhancing of the tumor.

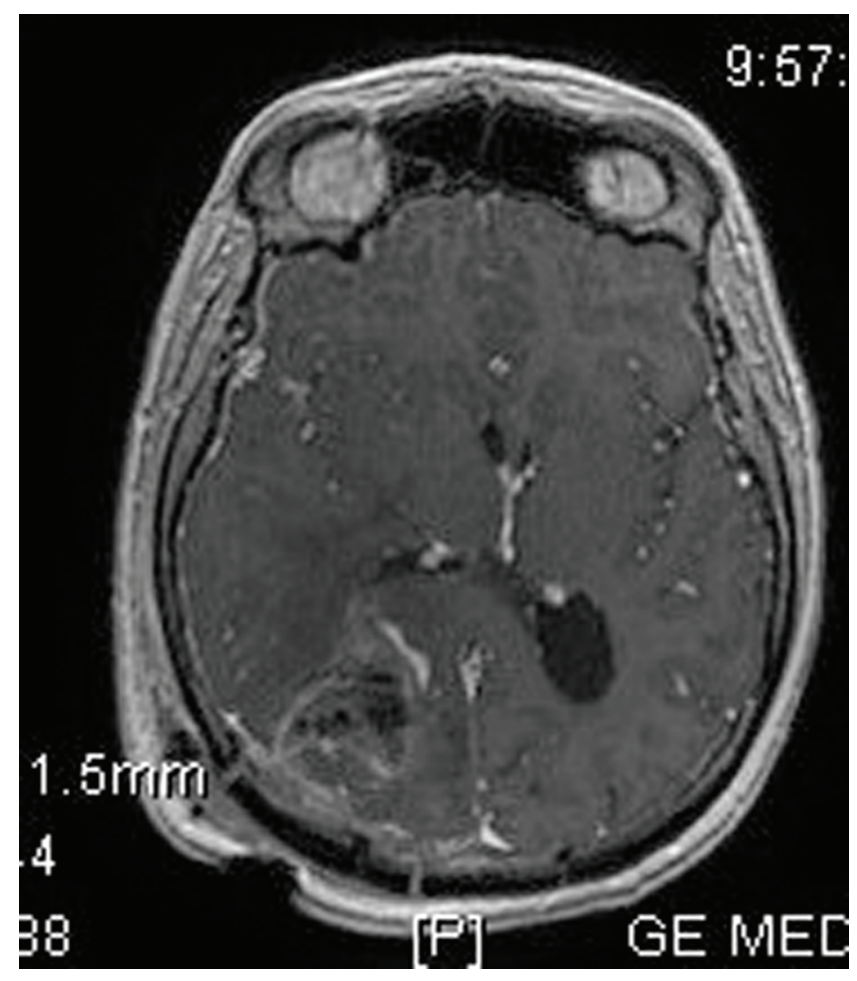

Figure 4. Post-operative brain MRI SPGR imaging which confirms the removal of the tumor. 

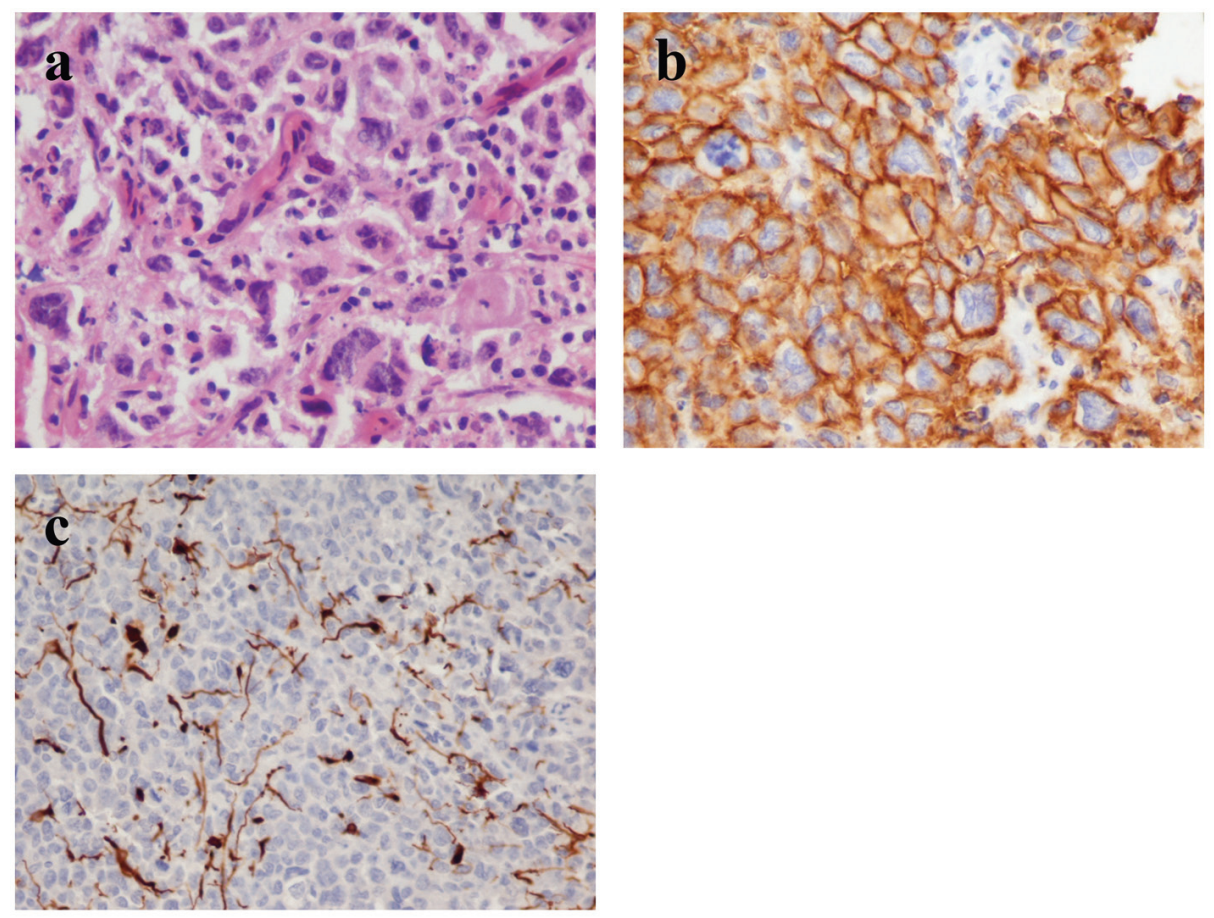

Figure 5. (a) Histology shows perivascular spread of highly anaplastic lymphoid cells with numerous mitotic figures (hematoxylin and eosin stain, original magnification $\times 40$ ). (b) The tumor cells express the pan-B-cell marker CD20 (immunohistochemistry, original magnification $\times 40$ ). (c) The malignant cells invade the parenchyma which demonstrates glial fibrillary-acid protein $($ GFAP) immunoreactivity (immunohistochemistry, original 15 magnification $\times 20$ ).

and had a history of dyslipidemia and allergy in amoxicillin. Also, in the past, the patient underwent a surgery on his right hip after a traffic accident that he had 2 years before.

His clinical examination showed increased reflexes of his left leg without other neurological findings. A brain CT scan without contrast was initially performed and revealed a lesion in his right parietal-occipital lobe. The additional intravenous administration of contrast medium showed that the dimensions of the lesion were $7.5 \times 2 \times 4.6 \mathrm{~cm}$. The contrast uptake and the density of the tumor were heterogeneous. There was also 1 $\mathrm{cm}$ middle line shift to the left as well as elevation of the right occipital horn. The patient had screws in his right hip, which were surgically removed in order to perform an MRI for further investigation of the tumor. MRI examination confirmed the existence of a lesion in the right occipital lobe, nearby the occipital horn compatible with the image of a low grade glioma (Fig. 1-3). The patient did not have any visual disorders as the opthalmologists reported before surgery. Also, blood exams did not reveal any numerical or functional disorders. The CT of the thorax, pelvis, upper and lower abdomen did not show any other pathological signs. The patient was scheduled for an occipital craniotomy for biopsy and depending on the result, resection or not of the lesion. Due to the inability of the biopsy to clarify the type of the tumor and considering the young age of the patient, we proceeded to surgical excision of the tumor. Intraoperative neuromonitoring (motorsensory and visual evoked potentials) and neuronavigation were used. The tumor was resected with the use of microscope and CUSA. A postsurgical MRI was performed after the operation and confirmed the subtotal excision of lesion (Fig. 4). CSF analysis did not reveal any pathological findings. Histopathological analysis revealed DLBCL (Fig. 5a-c) and the patient was referred to hematologists-oncologists of our hospital for further treatment manipulations. The patient was treated with radiotherapy and methotrexate and 16 months after his surgery is still tumor free.

\section{Discussion}

PCNSLs represent $0.7-1.7 \%$ of all malignant tumors and less than $5 \%$ of tumors arising within skull and spine [7, 14]. PCNSLs occur in more than $50 \%$ of cases in supra-tentorial areas $[7,15]$. PCNSLs are mainly DLBCL, thereby they are characterized by aggressiveness $[15,16]$. Diagnosis is established 3 6 months after the symptoms onset [7]. Patients have cognitive deficits, psychomotor slowing and mental alteration. Approximately $50 \%$ of cases have focal symptoms, headaches and increased intracranial pressure, while cranial nerve disorders and cerebellum or brainstem symptoms are present to the minority [15]. Differential diagnosis includes metastasis, glioma and toxoplasmosis, whereas in rare cases PCNSLs have signs of demyelinating disease [7].

Generally surgical excision should be avoided because these tumors are often cited in deep locations and therefore the risk of post-operative neurologic complications is increased $[17,18]$. Furthermore, several studies suggest that resection provides no benefit in survival of patients with PCNSL [12, 17]. Thus, surgical interventions are restricted to a stereotactic 
biopsy for diagnostic purposes only [17, 19]. It is important that the patient is not medicated with corticosteroid agents before biopsy takes place $[15,20]$. Corticosteroids can relieve the brain from the peritumoral edema, but they induce apoptosis of the tumor cells and therefore their administration prior to biopsy may preclude diagnosis $[15,21]$. In our case, the patient was under corticosteroid treatment before surgery and this may be a significant factor for the failure of identification in the biopsy. In the histopathologic examination, the tumor cells express CD19, CD20 and CD79a, whereas the majority expresses Bcl-6 and MUM1 and in some cases CD10 is expressed as well. The high mitotic activity leads to the increase of the MIB1, which can exceed 90\% [15]. Occasionally, necrosis is also noted in histopathologic analysis.

The disease has unfortunately poor prognosis and patients are expected to survive for 3 - 6 months without treatment, whereas chemotherapy alone or in combination with radiotherapy may improve median survival time to 25 - 60 months [7, 13]. It is apparent that younger patients (under the age of 60) and patients whose lymphoma does not affect meninges or the regions in proximity to ventricles have better prognosis [22]. The same applies to individuals whose immunity is normal [23]. Concentration of serum lactate dehydrogenase (LDH) is an independent prognostic marker [22]. Increased LDH and protein levels in CSF generally indicate poor prognosis [22].

Currently the standard treatment of PCNSL is high-dose methotrexate (HD-MTX)-based chemotherapy, which can be combined with whole-brain radiation (WBR) [24]. However, the employment of additional radiotherapy has been controversial due to its association with considerable neurotoxic effects $[18,25,26]$. It has been clearly indicated that the addition of WBR in first-line chemotherapy has a favorable role in progression-free survival (PFS) and some authors suggest that this also applies to overall survival (OS) [27-33]. Nevertheless, according to Thiel et al, the impact on OS is not significant and these results are also supported by several studies [27, 34, 35]. The omission of WBR from first-line treatment and its deferral until relapse of the disease may reduce treatment-related neurotoxicity and thus it is an acceptable and rational option for elderly patients, for whom the risk of neurologic impairment is higher compared to young patients [18, 24, 27-29, 36-38]. This approach however may not be the optimal solution for young patients, because the achievement of a prolonged PFS is a major therapeutic aim in this age population [17, 28, 39]. Moreover, Prica et al demonstrated that combined chemoradiotherapy significantly maximizes life expectancy and quality-adjusted life expectancy and proposed that this is the most suitable treatment for young patients [37]. Other therapeutic approaches that have been explored in order to diminish the neurotoxicity induced by additional WBR yielded quite promising results. These include low-dose WBR with tumor bed boost after chemotherapy [29], consolidation therapy with autologous stem-cell transplant [40] and pemetrexed as a single agent for elderly patients [41].

As previously mentioned, surgery is considered to have a limited role in the confrontation of PCNSL. However this notion is challenged in a secondary analysis of the G-PCNSLSG-1 trial, where PCNSL patients who underwent tumor resection achieved improved OS and PFS compared to biopsied patients. The favorable impact of resection regarding OS was less significant after adjustment for the number of lesions. Authors concluded that tumor removal should be considered in the treatment of lesions amenable to resection, especially in cases of single lesions [42]. According to Nishikawa, if the results of this study are valid, then tumor resection may represent a better approach for selected PCNSL cases than biopsy alone [43]. In a retrospective analysis of 248 patients [12], the 1-year survival rate was higher in patients who underwent complete excision than in those who underwent stereotactic biopsy and although this result was not statistically significant, it could imply therapeutic benefit $[19,44]$. Case reports have presented patients successfully treated with tumor excision. Sonstein et al reported a patient who survived over 5 years disease-free following complete tumor excision and a short course of steroid treatment [45]. Davies et al described a patient who survived over 20 years after total resection of his tumor [46]. Trapella et al presented a patient who remained tumor-free 79 months after total tumor removal and combined chemoradiotherapy [47]. Furthermore, in a study of 32 patients, Bellinzona et al concluded that surgery may be beneficial for patients with large-single space occupying lesions and progressive deterioration of neurologic status [48]. Tumor removal should also be considered in cases with the risk of imminent brain herniation [19]. Clinical experience of several researchers has shown the potential positive role of surgery in facilitation of glucocorticoid tapering, eradication of drug-resistant cell populations and alleviation of mass effect in cases of accessible, well-circumscribed lesions [49]. Previous studies that support the inferiority of surgery may no longer be sufficient to assess its curative role, because the technical advances in neurosurgery and the amelioration of adjuvant treatments have contributed to the efficiency and safety of surgical resections $[42,50]$. Therefore, future studies should be conducted in order to evaluate extent of tumor removal in PCNSL patients [51].

\section{Conclusion}

Although surgery is not the gold standard treatment for DLBCL tumors, presurgical imaging and clinical evidence in our case were not indicative for primary lymphoma. Also, this lesion was reachable for surgical excision as a single one with minimal danger for neurological deficits. The successful treatment management of our case may raise the question of early surgical excision in single primary lymphomas when they are located in non-eloquent areas. We concur that future prospective studies should be performed to further evaluate the capacity of surgery in the treatment of PCNSLs.

\section{Conflicts of Interest}

Authors declare that they do not have any conflicts of interest.

\section{Abbreviations}

PCNSL: primary central nervous system lymphoma; DLBCL: 
diffuse large B-cell lymphoma; CNS: central nervous system

\section{References}

1. Abbi KK, Muzaffar M, Gaudin D, Booth RL, Jr., Feldmeier JJ, Skeel RT. Primary CNS lymphoplasmacytic lymphoma: a case report and review of literature. Hematol Oncol Stem Cell Ther. 2013;6(2):76-78.

2. Ueba T, Okawa M, Abe H, Inoue T, Takano K, Hayashi $\mathrm{H}$, Nabeshima K, et al. Central nervous system marginal zone B-cell lymphoma of mucosa-associated lymphoid tissue type involving the brain and spinal cord parenchyma. Neuropathology. 2013;33(3):306-311.

3. Ney DE, Deangelis LM. Management of central nervous system lymphoma. In: Non- Hodgkin Lymphomas. Philadelphia: Lippincott Willilams \& Wilkins, 2010;527-539.

4. Report of Brain Tumor Registry of Japan (1984-2000). Neurol Med Chir (Tokyo). 2009;49(Suppl):PS1-96.

5. Shenkier TN, Blay JY, O'Neill BP, Poortmans P, Thiel E, Jahnke K, Abrey LE, et al. Primary CNS lymphoma of T-cell origin: a descriptive analysis from the international primary CNS lymphoma collaborative group. J Clin Oncol. 2005;23(10):2233-2239.

6. Louis DN, Ohgaki H, Wiestler OD, Cavenee WK, Burger PC, Jouvet A, Scheithauer BW, et al. The 2007 WHO classification of tumours of the central nervous system. Acta Neuropathol. 2007;114(2):97-109.

7. Mehmet Basmaci, Askin Esen Hasturk, Tulu Ayata. Management of Primary Diffuse Large B-Cell Lymphoma of the Central Nervous System: Clinical Study. Journal of Neurological Sciences (Turkish). 2013;30(2):469-476.

8. Cabanillas F. How important is whole brain radiotherapy for treatment of primary CNS lymphoma? Lancet Oncol. 2010;11(11):1011-1012.

9. Kluin, PM, Deckert, M, Ferry, JA. Primary diffuse large B-cell lymphoma of the CNS. In: WHO Classification of Tumours of Haematopoietic and Lymphoid Tissues, 2008; WHO Lyon, p.240-241.

10. Liao CH, Lin SC, Hung SC, Hsu SP, Ho DM, Shih YH. Primary large B-cell lymphoma of the fourth ventricle. J Clin Neurosci. 2014;21(1):180-183.

11. Schlegel U. Primary CNS lymphoma. Ther Adv Neurol Disord. 2009;2(2):93-104.

12. Bataille B, Delwail V, Menet E, Vandermarcq P, Ingrand P, Wager M, Guy G, et al. Primary intracerebral malignant lymphoma: report of 248 cases. J Neurosurg. 2000;92(2):261-266.

13. Juergens A, Pels H, Rogowski S, Fliessbach K, Glasmacher A, Engert A, Reiser M, et al. Long-term survival with favorable cognitive outcome after chemotherapy in primary central nervous system lymphoma. Ann Neurol. 2010;67(2):182-189.

14. Brar R, Prasad A, Sharma T, Vermani N. Multifocal lateral and fourth ventricular B-cell primary CNS lymphoma. Clin Neurol Neurosurg. 2012;114(3):281-283.

15. Baraniskin A, Deckert M, Schulte-Altedorneburg G, Schlegel U, Schroers R. Current strategies in the diagnosis of diffuse large B-cell lymphoma of the central nerv- ous system. Br J Haematol. 2012;156(4):421-432.

16. Brito AB, Reis F, de Souza CA, Vassallo J, Lima CS. Intracranial primary dural diffuse large B-cell lymphoma successfully treated with chemotherapy. Int J Clin Exp Med. 2014;7(2):456-460.

17. Abrey LE, Batchelor TT, Ferreri AJ, Gospodarowicz M, Pulczynski EJ, Zucca E, Smith JR, et al. Report of an international workshop to standardize baseline evaluation and response criteria for primary CNS lymphoma. J Clin Oncol. 2005;23(22):5034-5043.

18. DeAngelis LM, Yahalom J, Heinemann MH, Cirrincione C, Thaler HT, Krol G. Primary CNS lymphoma: combined treatment with chemotherapy and radiotherapy. Neurology. 1990;40(1):80-86.

19. Elder JB, Chen TC. Surgical interventions for primary central nervous system lymphoma. Neurosurg Focus. 2006;21(5):E13.

20. Agarwal PA, Menon S, Smruti BK, Singhal BS. Primary central nervous system lymphoma: a profile of 26 cases from Western India. Neurol India. 2009;57(6):756-763.

21. Roth P, Wick W, Weller M. Steroids in neurooncology: actions, indications, side-effects. Curr Opin Neurol. 2010;23(6):597-602.

22. Ferreri AJ, Blay JY, Reni M, Pasini F, Spina M, Ambrosetti A, Calderoni A, et al. Prognostic scoring system for primary CNS lymphomas: the International Extranodal Lymphoma Study Group experience. J Clin Oncol. 2003;21(2):266-272.

23. Song MK, Chung JS, Joo YD, Lee SM, Oh SY, Shin DH, Yun EY, et al. Clinical importance of Bcl-6-positive nondeep-site involvement in non-HIV-related primary central nervous system diffuse large B-cell lymphoma. J Neurooncol. 2011;104(3):825-831.

24. Phillips EH, Fox CP, Cwynarski K. Primary CNS lymphoma. Curr Hematol Malig Rep. 2014;9(3):243-253.

25. Correa DD, Shi W, Abrey LE, Deangelis LM, Omuro AM, Deutsch MB, Thaler HT. Cognitive functions in primary CNS lymphoma after single or combined modality regimens. Neuro Oncol. 2012;14(1):101-108.

26. Doolittle ND, Korfel A, Lubow MA, Schorb E, Schlegel $\mathrm{U}$, Rogowski S, Fu R, et al. Long-term cognitive function, neuroimaging, and quality of life in primary CNS lymphoma. Neurology. 2013;81(1):84-92.

27. Thiel E, Korfel A, Martus P, Kanz L, Griesinger F, Rauch M, Roth A, et al. High-dose methotrexate with or without whole brain radiotherapy for primary CNS lymphoma (G-PCNSL-SG-1): a phase 3, randomised, non-inferiority trial. Lancet Oncol. 2010;11(11):1036-1047.

28. Omuro A, Taillandier L, Chinot O, Sierra Del Rio M, Carnin C, Barrie M, Soussain C, et al. Primary CNS lympho$\mathrm{ma}$ in patients younger than 60: can whole-brain radiotherapy be deferred? J Neurooncol. 2011;104(1):323-330.

29. Kim BH, Kim IH, Park SH, Park CK, Jung HW, Kim TM, Lee $\mathrm{SH}$, et al. Low-dose whole brain radiotherapy with tumor bed boost after methotrexate-based chemotherapy for primary central nervous system lymphoma. Cancer Res Treat. 2014;46(3):261-269.

30. Kasenda B, Ferreri AJ, Marturano E, Forst D, Bromberg J, Ghesquieres H, Ferlay C, et al. First-line treatment and 
outcome of elderly patients with primary central nervous system lymphoma (PCNSL)--a systematic review and individual patient data meta-analysis. Ann Oncol. 2015;26(7):1305-1313.

31. Aki H, Uzunaslan D, Saygin C, Batur S, Tuzuner N, Kafadar A, Ongoren S, et al. Primary central nervous system lymphoma in immunocompetent individuals: a single center experience. Int J Clin Exp Pathol. 2013;6(6):10681075.

32. Piao YZ, Li P, Liu Q, Li WL. [The clinical analysis of primary central nervous system lymphoma in 23 patients]. Zhonghua Nei Ke Za Zhi. 2011;50(11):954-957.

33. Birnbaum T, Bochmann K, von Baumgarten L, Straube A. Early relapses in patients with primary CNS lymphoma treated with methotrexate-based chemotherapy without consolidating whole brain irradiation. J Neurooncol. 2013;112(2):233-239.

34. Korfel A, Thiel E, Martus P, Mohle R, Griesinger F, Rauch M, Roth A, et al. Randomized phase III study of whole-brain radiotherapy for primary CNS lymphoma. Neurology. 2015;84(12):1242-1248.

35. Dalia S, Forsyth P, Chavez J, Price S, Shah B, Bello C, Sokol L, et al. Primary B-cell CNS lymphoma clinicopathologic and treatment outcomes in 89 patients from a single tertiary care center. Int J Hematol. 2014;99(4):450456.

36. Ichikawa T, Kurozumi K, Michiue H, Ishida J, Maeda Y, Kondo E, Kawasaki A, et al. Reduced neurotoxicity with combined treatment of high-dose methotrexate, cyclophosphamide, doxorubicin, vincristine and prednisolone (M-CHOP) and deferred radiotherapy for primary central nervous system lymphoma. Clin Neurol Neurosurg. 2014;127:106-111.

37. Prica A, Chan K, Cheung MC. Combined modality therapy versus chemotherapy alone as an induction regimen for primary central nervous system lymphoma: a decision analysis. Br J Haematol. 2012;158(5):600-607.

38. Gavrilovic IT, Hormigo A, Yahalom J, DeAngelis LM, Abrey LE. Long-term follow-up of high-dose methotrexate-based therapy with and without whole brain irradiation for newly diagnosed primary CNS lymphoma. J Clin Oncol. 2006;24(28):4570-4574.

39. Lamborn KR, Yung WK, Chang SM, Wen PY, Cloughesy TF, DeAngelis LM, Robins HI, et al. North American Brain Tumor Consortium. Progression-free survival: an important end point in evaluating therapy for recurrent high-grade gliomas. Neuro-Oncology. 2008;10(2):162170.

40. Omuro A, Correa DD, DeAngelis LM, Moskowitz CH, Matasar MJ, Kaley TJ, Gavrilovic IT, et al. R-MPV followed by high-dose chemotherapy with TBC and autologous stem-cell transplant for newly diagnosed primary CNS lymphoma. Blood. 2015;125(9):1403-1410.

41. Han S, Wang M, Liu B, Yu J. Pemetrexed for primary central nervous system lymphoma in the elderly. Clin Transl Oncol. 2015.

42. Weller M, Martus P, Roth P, Thiel E, Korfel A. Surgery for primary CNS lymphoma? Challenging a paradigm. Neuro Oncol. 2012;14(12):1481-1484.

43. Nishikawa R. Resection of PCNSL, if safely possible, seems to be better than biopsy: challenging a paradigm? Neuro Oncol. 2012;14(12):1423.

44. Liu BL, Cheng JX, Zhang X, Zhang W, Cheng H. Limited role of surgery in the management of primary central nervous system lymphoma (Review). Oncol Rep. 2009;22(3):439-449.

45. Sonstein W, Tabaddor K, Llena JF. Solitary primary CNS lymphoma: long term survival following total resection. Med Oncol. 1998;15(1):61-65.

46. Davies KG, Cole GC, Weeks RD. Twenty-year survival following excision of primary CNS lymphoma without radiation therapy: case report. Br J Neurosurg. 1994;8(4):487-491.

47. Trapella G, Fabi S, Migliore A, Bianchini E, Cavazzini L. Primary central nervous system lymphoma: a case of long survival. Ital J Neurol Sci. 1988;9(3):275-278.

48. Bellinzona M, Roser F, Ostertag H, Gaab RM, Saini M. Surgical removal of primary central nervous system lymphomas (PCNSL) presenting as space occupying lesions: a series of 33 cases. Eur J Surg Oncol. 2005;31(1):100105.

49. Rubenstein JL, Gupta NK, Mannis GN, Lamarre AK, Treseler P. How I treat CNS lymphomas. Blood. 2013;122(14):2318-2330.

50. Bierman PJ. Surgery for primary central nervous system lymphoma: is it time for reevaluation? Oncology (Williston Park). 2014;28(7):632-637.

51. Doucet S, Kumthekar P, Raizer J. Primary central nervous system lymphoma. Curr Treat Options Oncol. 2013;14(2):185-197. 